Cahiers $d u$ MONDE RUSSE

\section{Cahiers du monde russe}

Russie - Empire russe - Union soviétique et États indépendants

$43 / 4 \mid 2002$

Intellectuels et intelligentsia

\title{
Marie-Pierre Rey, Le dilemme russe
}

\section{Alain Blum}

\section{OpenEdition \\ Journals}

Édition électronique

URL : https://journals.openedition.org/monderusse/4068

DOI : $10.4000 /$ monderusse. 4068

ISSN : $1777-5388$

\section{Éditeur}

Éditions de l'EHESS

\section{Édition imprimée}

Date de publication : 30 décembre 2002

Pagination : 832-835

ISBN : 2-7132-1796-2

ISSN : $1252-6576$

\section{Référence électronique}

Alain Blum, " Marie-Pierre Rey, Le dilemme russe », Cahiers du monde russe [En ligne], 43/4 | 2002, mis en ligne le 18 juin 2009, consulté le 04 septembre 2022. URL : http://journals.openedition.org/ monderusse/4068; DOI : https://doi.org/10.4000/monderusse.4068

Ce document a été généré automatiquement le 4 septembre 2022

Tous droits réservés 


\title{
Marie-Pierre Rey, Le dilemme russe
}

\author{
Alain Blum
}

\section{RÉFÉRENCE}

Marie-Pierre REY, Le dilemme russe. La Russie et l'Europe occidentale d'Ivan le Terrible à Boris Eltsine. Paris, Flammarion, 2002, 354 p.

1 L'ambition de cet ouvrage est vaste puisqu'il couvre une période allant du milieu du $\mathrm{XVI}^{\mathrm{e}}$ siècle jusqu'à aujourd'hui et traite une question dont on connaît la centralité : les relations entre la Russie et l'Europe, et surtout l'attitude de la Russie vis-à-vis des États européens. Marie-Pierre Rey tient aussi à aborder en continuité le $\mathrm{xx}^{\mathrm{e}}$ siècle et ceux qui précèdent. Ici, l'histoire soviétique est vue comme une prolongation de l'histoire russe. Enfin, l'auteur suit une voie particulière, proposant une histoire des relations entre Russie et Europe avant tout déterminée au sommet du pouvoir, dissociée fortement de l'histoire intérieure.

2 L'auteur débute par un rapide panorama de la place de la Russie en Europe, du Moyen Âge jusqu'au xvi ${ }^{e}$ siècle, entre la Russie kiévienne et Ivan III. Elle souligne que, dès sa fondation, le développement de l'état russe, en décalage chronologique avec l'histoire européenne, conduit la Russie à hésiter en permanence sur la nature des relations qu'elle souhaite établir avec l'Europe. L'invasion mongole lui apparaît ainsi comme un moment fondateur de la difficulté à penser de façon continue et intégrée l'espace européen. Cette particularité ne disparaît pas avec la naissance de l'État russe autour de Moscou et le règne d'Ivan III. Marie-Pierre Rey voit une première rupture lors du règne d'Ivan IV, qui exprime au mieux cette hésitation entre le repli sur elle-même ou ses voisins immédiats et l'ouverture sur l'Occident. Ivan IV apparaît ainsi comme tenté par l'ouverture à l'Ouest, mais son règne, qui séduit d'abord, finit par repousser par son caractère autocratique. Le contraste entre les tentatives ébauchées au début de ce règne et ce qui en a résulté par la suite exprime une constante de l'histoire des relations entre Russie et Europe occidentale. Ces contradictions perdurent, après le Temps des Troubles, jusqu'à la fin du XvII siècle. 
3 La « révolution pétrovienne » est bien entendu étudiée en détail, symbole confirmé d'une transformation, déjà engagée mais alors systématisée, des relations avec l'Occident. Les grandes réformes du règne de Pierre sont ici mises en perspective avec les lentes mutations qui précèdent, et qui contribuent à créer un nouvel État. La Russie, devenue grande puissance européenne, semble désormais clairement intégrée à cet ensemble. Pierre paraît en être l'artisan essentiel, comme, plus tard, les transformations des relations entre l'Europe et la Russie seront lues à travers les changements de règnes.

Ainsi, durant le règne des impératrices, de Catherine $\mathrm{I}^{\text {re }}$ à Catherine II, les alliances se transforment au gré de ces successions. Cependant l'expansionnisme vers l'Ouest, engagé par Pierre, perdure et il est même renforcé par Catherine II. Or, selon l'auteur, celui-ci conduit à renforcer la relation entre Russie et Europe, à rapprocher et surtout à inclure la première dans la seconde. Les jeux diplomatiques qui y sont associés, l'intérêt porté aux territoires acquis, la participation des Baltes et des Allemands à la conduite de l'empire en témoignent. Cela contribue à moderniser l'État, même si ces réformes sont imposées d'en haut. Toutefois, Marie-Pierre Rey souligne cette éternelle difficulté des réformes de l'empire, qui, même si elles touchent le fonctionnement de l'État, ne réussissent pas à s'étendre au social et aux formes les plus directes du pouvoir, lequel reste autocratique. D'un côté un « modèle européen » se " généralise au sein des élites nobiliaires ", modèle «véhiculé par les hautes sphères de l'État et approché par les armées russes lors des campagnes militaires en terres occidentales ", d'un autre côté la « dérussification » des élites, interprétée soit comme occidentalisation soit comme subversion, fragilise cette ouverture sur l'Europe et cette intégration.

5 La puissance diplomatique de la Russie va, ensuite, se faire de plus en plus évidente aux yeux de l'ensemble des pays européens, dans la première moitié du XIX ${ }^{\mathrm{e}}$ siècle, du règne de Paul $I^{\text {er }}$ à celui de Nicolas $I^{\text {er }}$. Quelles que soient les positions et les ambitions des tsars, quelles que soient l'hostilité ou la faveur dont jouissent les pays européens, ainsi que le prix à payer à cette puissance, la Russie joue à l'évidence une place majeure en Europe. Cette période est toutefois marquée par une tension, persistante, entre le regard intérieur et les innovations de la politique extérieure. Elle est aussi marquée par un renouveau des critiques face à une occidentalisation du comportement des élites et de la diplomatie, et donc par la volonté de repli de la Russie sur elle-même. Cette tension semble se résoudre au début de la période suivante, lorsque Alexandre II cherche à mettre en conformité la place désormais acquise de la Russie parmi les nations européennes et les transformations sociales et politiques à l'intérieur même de son pays. Mais la Russie retombe alors dans cette crainte d'une réforme politique trop profonde, dont le conservatisme des règnes d'Alexandre III et de Nicolas II sera la plus éclatante conséquence. Ainsi, si l'ouverture vers l'Europe occidentale est avérée, elle reste surtout posée sur un plan diplomatique, écartelant de la sorte la Russie entre deux pôles contradictoires.

6 Marie-Pierre Rey cherche ensuite à ne pas interrompre les logiques qu'elle a décrites et analysées pour entrer dans la période soviétique. Ceci ne signifie pas que la relation entre la Russie et l'Europe après 1917 soit en continuité avec l'Ancien Régime. Elle souligne en particulier qu'une inversion totale s'établit. Alors que toute l'histoire de l'empire était marquée par cette attraction-répulsion envers le modèle occidental, c'est désormais le modèle soviétique qui est la référence, avec le même pouvoir de répulsion ou d'attraction. Cette "inversion idéologique ", même si elle va subsister durant toute la période soviétique, ne signifie pas que les relations entre l'URSS et l'Europe soient en 
rupture brutale avec ce qui précédait. Cette période, ainsi que les suivantes, font d'ailleurs plus de place aux hommes qui participent à ces relations, les profils de đi@erin, aussi bien que de Rakovskij ou de Litvinov permettant de mieux les éclairer. L'ouvrage montre bien aussi la double politique qui s'établit, l'une autour des Affaires étrangères, fondée sur une diplomatie de puissance tournée vers l'Europe, l'autre autour du développement du Komintern et donc en rupture avec les formes traditionnelles. Ces tensions et contradictions dépasseront la période stalinienne, et un dernier chapitre traite de l'après-Stalin qui se caractérise aussi, comme l'ère précédente, par une opposition entre trois pôles : « coopération, partenariat et subversion ». Cependant cette époque est, selon l'auteur, la première où, depuis 1917, l'URSS « commence à s'ouvrir sur l'Europe occidentale, tant sur le plan politique et économique que culturel ». Mais cette ouverture conduit aussi à des raidissements internes remettant en cause le fonctionnement du système dans son ensemble. On regrettera ici un chapitre trop bref, traitant de Hruščev et Brežnev, d'autant plus que l'auteur propose de nombreuses pistes stimulantes sur cette période encore peu relue ces dernières années.

Cette très vieille contradiction entre ouverture extérieure et raidissements trouve peutêtre une issue dans la fin de l'URSS, sur laquelle, en quelques pages, se conclut cette histoire. L'immensité de la question explique aisément que Marie-Pierre Rey ait choisi de n'en traiter qu'un des aspects, celui de la position essentiellement diplomatique et politique des divers dirigeants russes, et surtout des tsars, puis des plus hauts responsables soviétiques et russes, vis-à-vis de l'Europe. Sans doute, derrière ce problème, l'auteur s'interroge-t-elle, comme elle le fait dans son introduction, sur l'identité russe. Mais l'objet central de cet ouvrage reste la scène diplomatique, et surtout le "point de vue des acteurs politiques de ces relations, les décideurs gouvernants, diplomates - mais en tenant compte aussi des acteurs sociaux et culturels (philosophes, journalistes, écrivains) ». L'auteur insiste sur le fait qu'on peut comprendre la relation entre Russie et Europe à travers l'interprétation des décisions de quelquesuns, décisions souvent indépendantes, voire contradictoires, avec celles qui ont trait à la politique intérieure. C'est vrai lorsqu'il s'agit de cerner la politique extérieure menée par Lenin ou par Stalin, incluant ses choix de rapprochements avec les puissances occidentales, au début de cette décennie, tout en renforçant le Komintern, et en mettant en place une politique répressive de plus en plus violente à l'intérieur. C'est aussi vrai des politiques d'ouverture suivies autant par Pierre, Catherine II ou Alexandre $\mathrm{I}^{\text {er }}$, qui souvent ne sont pas exemptes de profondes contradictions avec la politique intérieure.

Cette hypothèse montre qu'il est indispensable de mieux comprendre les ressorts des décisions de rapprochement, de construction d'une puissance, ou de fermeture, qui sont décrits dans cet ouvrage. On regrettera sans doute que ces décisions soient souvent réduites à des choix pris tout en haut de l'appareil d'État, sans que les retournements soient bien saisis. Cela tient sans doute à l'usage, que nous trouvons personnellement regrettable, du terme de "décideur» pour caractériser ceux qui déterminent les politiques vis-à-vis de l'Europe. Il n'apporte rien, d'autant qu'on ne sait pas quels acteurs il désigne, et quelles relations s'établissent, précisément, entre l'appareil diplomatique, l'appareil politique, et la société. Ce livre suggère que l'analyse de la politique internationale devrait, de plus en plus, s'appuyer sur l'étude de ceux qui en déterminent les orientations, leurs parcours et leur formation, mais que celle-ci ne suffit pas à comprendre les grandes transformations ni les continuités, et qu'un processus autonome, développé par le cercle le plus central du pouvoir, se déroule aussi, indépendamment de ces personnages. Il faut donc bien comprendre les connexions existant entre ces 
différents lieux, pour en cerner les transformations et les apparentes contradictions. Outre une synthèse de sept siècles de relations entre la Russie et l'Europe, cet ouvrage suscite donc des questions indispensables pour orienter les recherches contemporaines en ces termes. 